\title{
Getting down to writing up: navigating from the field to the desk and the (re)presentation of fieldwork
}

\author{
By Paul O’Hare (University of Sheffield)
}

The writing of a thesis comes at the end of a long and, for some of us, torturous journey. It is in the thesis that we must present the research process, defending the methodology that was utilised, and explain our insights and conclusions. Writing up is the stage at which we must make order and sense out of what is usually a messy research project. Yet at the same time, it is clear that the write-up is not necessarily a straightforward reflection of our actions; it is not simply a matter of reporting how we 'did' research. Furthermore, our approach to the write-up is itself a critical methodological consideration. For instance, the presentation of material, deciding what to include and exclude in a final manuscript, is subjective and frequently becomes a source of concern and self-doubt. Writing represents the 'end game' when we can no longer be cautious regarding our thoughts and must commit to paper what had hitherto been ethereal. As such, it often represents a psychological leap of faith in our own minds and this can bring with it many challenges. In this paper I examine these issues in more detail by reflecting upon my own doctoral thesis write-up, in particular, the writing of my empirical chapters. I consider both how I was troubled by my leaving the field and insecurities that this entailed. I secondly turn to consider the practical difficulties faced in writing up complicated and lengthy case study chapters. In so doing, I illustrate how, rather than representing obstacles to the completion of the thesis, such challenges can in fact produce a more balanced and reflexive research write-up.

\section{Introduction}

'Doing a $\mathrm{PhD}$ ' is a complicated and challenging business, as is most apparent when we turn our attention to writing up. It is at this point, as I have discovered recently, that we are forced to not only make sense of our study, but to do so in a manner that is transparent and communicable to others. Leaving aside for a moment the looming realisation that the completion deadline is creeping ever closer and the unease and the personal insecurity that this produces, there is the obvious and acute awareness that the thesis contains the text through which we will be held to account and ultimately against which we shall have our academic credentials examined. No matter how innovative the research, or the value it may hold to the sphere of academia to which it is related, it is through the thesis alone that we must record and present our efforts. It represents the culmination of at least three years of work and there is a huge responsibility, more often than not self-inflicted, to serve justice to what so much time and energy has been invested into. By consequence, the thesis and its composition also embodies a significant emotional investment.

This paper charts my experiences as I approached my own thesis write-up. The process of writing and the resultant product varies from person to person, across 
disciplines and even within departments. Many elements of this reflective account are therefore unique to my own experience. I have, however, organised this paper into broader themes that will hopefully resonate with other doctoral students. I do not, however, offer explicit guidance regarding how I dealt with the issues-indeed I myself have yet to resolve many of these concerns. It is, rather, an opportunity to explore some of the challenges more deeply from my personal perspective. I pay particular attention to the writing up of my research findings, which formed two chapters, each reporting an independent qualitative case study. These were the first elements of my thesis that were written in a comprehensive fashion.

This paper is organised into two broad, yet interrelated sections. The first considers the often-overlooked concerns and issues created by a move from generating and collecting data in the field to the desk-bound writing process. In the second section I turn to my case study write-ups and examine in more detail how I started and sustained these chapters and assess how the pressures encountered during the drafting process affected me. By way of background I begin with a brief synopsis of my research.

\section{Background to my research}

My research, in the field of town planning at the University of Sheffield, United Kingdom, was funded by the Economic and Social Research Council (ESRC). Entitled Public Participation in the Planning System: Learning from the Grassroots, it examines how 'grassroots' or community based civic bodies interact with the state, other voluntary bodies, and their own 'constituencies', in the management and governance of localities. The study focuses on issues regarding public participation and democratic involvement, the role of the civic sector in the delivery and facilitation of services, and partnership building between community organisations and statutory bodies. It centred on two case study groups, one based in an urban area of South Yorkshire and the other in a predominantly rural area of Derbyshire. It drew upon a range of qualitative methodological techniques: participant observation of meetings and other ethnographic activities, documentary analysis, and around 40 semistructured interviews with key members of the community groups, statutory bodies, and other actors. I had identified conceptual themes for the assessment of the data through the drafting of an analytical framework before I entered the field although, as with most such studies, this was not set in stone; many aspects of the research were both flexible and exploratory.

The doctorate followed a traditional British format with a first year spent in project formulation, that is identifying and reviewing appropriate bodies of literature and developing research questions, a second year in 'the field', also interspersed with preliminary data analysis and a third year spent on intensive data analysis and thesis drafting. Around three months into my third year I took a six-month 'break' to pursue an ESRC secondment. Therefore, when I started writing the case chapters in earnest in August 2006, almost two years had passed since the commencement of the fieldwork.

\section{Negotiating the move from the field to the office}

During my fieldwork I spent around six months intensively 'following' my case study organisations, attending their internal meetings and their encounters with statutory and other voluntary bodies, mainly through the use of participant observation, with a 
further six months spent conducting rather less intensive ethnography, writing up preliminary findings and in preparing for interviews. The research, as with most ethnographic projects, was both concentrated and challenging. Both case studies operated in politically charged environments and consisted of dedicated and opinionated individuals who had passionate and often adversarial relationships with other groups and statutory bodies. I was granted, for the most part, full access to the groups' activities and leaders, enabling me to build a personal rapport and lasting relations with many group members. As a result, I felt a great deal of empathy with the groups, and although I sometimes disagreed with some of their activities (thoughts I kept to myself at the time), I genuinely supported their core aspirations and goals, namely to make their areas safer, healthier and happier places to live. That said, at times I also received the impression that some members of the groups were a little wary of my 'true' intentions. Some regarded my keen interest in the group's affairs as a little peculiar and, particularly during the more challenging times for the group, I am quite sure that my presence and inquisitiveness was somewhat of an irritation.

I became thoroughly enthused in the maelstrom of community politics. I observed and in many instances shared with case studies their highs and lows, their frustrations and achievements, and even observed one group's fight for survival in the face of bureaucratic regulations, tight funding regimes, and internal feuds and fractures. The research was rewarding and informative yet also overwhelming and, at times, disenchanting. The whole process was both captivating and consuming. To an extent I was relieved to leave the field and to return to my office (see Hammersley and Atkinson 2006:122 for a further discussion of this). I looked forward to turning off my recorder after the final batch of interviews, and anticipated the feeling of emancipation from the research. In a practical sense, I would no longer be bound by public transport timetables or the dates of meetings. I believed that I would also finally feel comfortable in the knowledge that the information I required to finish my research was now in my possession. I would not have to rely upon others, or ensure links and good relations were retained with the groups (for a further discussion of the 'tiring' anxiety of fieldwork, see Lareau 1996:218-220). I could, I insisted to myself, regain control of my research and finally (re)assert my ownership over the project. Ultimately, I could draw a line under a substantial aspect of the doctorate. My fieldwork would be finished, at long last!

Yet, despite my relief at leaving the field, and even though I was looking forward to immersing myself in the analysis and writing, there lingered at the back of my mind a strong desire to return to the field. Whilst my primary research on them had finished, the cases remained, evolving and changing, developing new interests and entering new, interesting and potentially enlightening relationships. Having now had time to consider these feelings, I realise that my desire to retain close links to the groups served other purposes also. I had a persistent concern that there remained data waiting to be collected in the field. I believed that perhaps another chat with certain actors, or the attendance of a more events, could provide yet another seam of material to further enrich my analysis. It was comforting to know that when I encountered a gap in my knowledge or understanding, sustained links with the cases would provide opportunities for return to the field, or to at least permit a distant monitor of their activities, a sentiment that it would seem even experienced researchers encounter:

It can therefore be difficult for the researcher to decide finally to leave the organization, to gather no more information, and to begin the process of analysing and documenting what data have been collected. This can be an 
awkward psychological leap, as there is always the possibility, usually a strong probability, that vital information has been overlooked. (Buchanan, Boddy and McCalman 1988:64)

This feeling was exacerbated by the fact that my cases were becoming increasingly involved in controversial regeneration issues and both were periodically reported in the local press as protagonists in local disputes. Such matters clearly were important to 'my subjects' and those they claimed to represent and, by extension, they interested me.

As I returned to the process of writing and began to realise just how daunting this was, the field suddenly appeared to be rather less intimidating than it did whilst I was there. I had, in the short time since leaving the field, assumed a faint nostalgic warmth towards it. This is, I can now surmise, most likely due to the familiarity I had developed towards the cases. I knew more about my research subjects than most. In contrast, writing up was an unknown and daunting task, particularly the prospect of making sense of and representing the cases. It took some time to adjust to my new tasks and to accept that my role and duties had evolved. Hammersley and Atkinson discuss these issues in further detail:

As the fieldwork progresses, however, the researcher becomes inescapably familiar with the setting, and the accumulated fieldnotes and transcripts represent a physical record of that familiarity. Before embarking on any major writing up, therefore, one has to undertake a further task of estrangement. If one does not distance oneself from them, then there is a danger of being unable to dismantle the data, select from them and re-order the material. One is left in the position of someone who, when asked to comment on and criticize a film or novel, can do no more than rehearse the plot. The ethnographer who fails to achieve distance will easily fall into the trap of recounting 'what happened' without imposing a coherent thematic or analytic framework. (Hammersley and Atkinson 1983:212-13)

Upon reflection, many of the anxieties that I felt at this time were not unwarranted. There were aspects of the cases and nuances in the detail that I did not fully understand, and the very fact that the groups remained accessible acted both as an opportunity for escape from the office and the intense task of drafting, and a psychological crutch. I could, if required, or by way of distraction, nip back to the field for a catch-up, a cup of tea, to ask just one more question, or just to see how things were going. In short, I found it hard to let go of the field and to get on with writing, a feeling that was not unknown by fellow researchers. Once, when a member of staff in my department asked me how it was going shortly after what was to be my last interview and I said that I had finally 'finished' my fieldwork, I was returned a knowing smile and the comment, "Well, just be sure to resist the temptation to go back...'

There is no easy or definitive method of exiting the field once and for all. This is accentuated in more intensive studies in starkly different social or cultural contexts where a researcher must place a great deal of effort in going native, as discussed by, amongst others, Bacchiddu (2004:7), who, when reflecting upon her intensive anthropological study on a remote Chilean island community, commented:

The desire to feel part of the group and to succeed in creating ties - in order to conduct ... successful research - has unexpected emotional consequences. I had experienced the end of my fieldwork period as an abrupt rupture, a too sudden change, which I had no time to come to terms with before it was upon 
me. I did not feel, as often happens, that it was time to go. While I could have taken my sense of familiarity as a signal and a reminder that my research had reached a satisfactory point of completion and that it was time to move on, instead I dreaded the approaching separation.

In the weeks and months after my final interviews, as I became increasingly preoccupied with data analysis and writing, I fell out of daily contact with the groups and the temptation to return to the field gradually diminished. That is not to say that the desire was extinguished altogether. Instead, I had become engrossed in alternative activities. The $\mathrm{PhD}$ process was entering a new phase, and there was increasing pressure to write. I was also well aware that my supervisors would have expressed concern regarding any plans to return to the field.

I had told the groups that, at some point, I would feed back my results to them, but I became aware that some of my findings would not make for comfortable reading for participants. Some of the observations I had made regarding the groups' operations were far from complementary, and whilst I stopped short of criticising the organisations, and indeed felt much empathy with them, some observations were quite critical. I knew that anything I wrote not only ran the risk of unintentionally offending research subjects but, perhaps more worryingly, could potentially be used by the groups to legitimise their efforts or to criticise adversaries. These two issues, combined with the fact that group members probably would have found many of the less refined and rather tentative findings a little esoteric, meant that any 'formal' returns to the field would have to be both carefully considered and would involve time-consuming preparations. A few months after the research interviews I left Sheffield for six months to assume a secondment some 170 miles away in London. My entire $\mathrm{PhD}$ was, for the time being, shelved. Ultimately, it was at this point that I drew a line underneath my fieldwork, although I now too realise and have come to terms with the fact that my study can only provide a snapshot in time.

This section has illustrated how the move from the field to the write-up can be difficult to negotiate. Even though my research did not entail extremely intensive fieldwork in comparison with many other ethnographers or anthropologists, the field remained alluring long after the fieldwork had been 'completed'. I retained a deep sense of attachment to 'my' cases, partly due, as I have noted, to my awareness that field data is imperfect. Developing an ability to handle these apprehensions - in appreciating that the study can only provide a brief snapshot in time, and recognising the failings of my work without allowing such reflections to consume my thoughtsgradually helped ease my approach into writing.

\section{Presenting and representing the case studies}

My planned thesis structure included two or three literature review chapters, a methodology chapter which would include research questions and a framework for analysis (drawn from my literature), a chapter for each case study write-up, and a discussion chapter which would draw out the main findings of the analysis. Throughout the doctorate, my supervisors reminded me that my empirical chapters were the most critical elements of the research and would constitute the driving force of the thesis. Despite the (now obvious) central role the empirical work assumed in my doctorate I rather naively, and perhaps due to my six month 'break' from thesis writing, was rather more concerned with my grasp of the literature and, more particularly, in relating my findings to the academic concepts and debates that had 
formed the backdrop to my research. However, when I started to compose the case study reviews, I realised both how onerous this aspect of the writing was and its fundamental significance to the project as a whole.

I, like all of us, wanted my cases to be as representative and accurate as possible, as Hammersley and Atkinson note:

We cannot continue to regard the 'writing up' of ethnographic work as innocent. On the contrary, a thorough recognition of the essential reflexivity of ethnographic work intends to the work of reading and writing as well. We must take responsibility for how we choose to represent ourselves and others in the texts we write. (Hammersley and Atkinson 2006:258)

I wished to remain true to my research subjects; both members of the community groups, yet also other interviewees that were treated as adversaries by the groups. I felt that all my interviewees were open and honest, but given the nature of the research, many details were contested. I obviously felt a sense of ethical duty to report a rounded and balanced version of events that caused no malevolence to those I had engaged with. Murphy and Dingwall (2001), drawing on the work of Josselson (1996), further relate to the concern that researchers face when reporting on the lives of the researched:

The experience of being written about may be a matter of concern in its own right: 'I worry intensely about how people will feel about what I write about them. I worry about the experience of being "writ down", fixed in print, formulated, summed up, encapsulated in language, reduced in some way to what the words contain. Language can never contain a whole person, so every act of writing a person's life is inevitably a violation.' (Josselson 1996:62, cited in Murphy and Dingwall 2001:341)

On top of these issues, I was all too aware that drafting itself was a form of commitment - the moment when our thoughts must become transparent and ideas and insights are laid open to criticism. With these concerns in mind, when I sat down to the task of writing up my two case studies, I found it difficult to stop. In much the same way that I was reticent to leave the field and to draw a line underneath that aspect of the study, I was similarly fearful of 'missing something' in my write-up.

My supervisors, as well as former and current doctoral students, constantly reminded me that there was no right or wrong way to draft case study chapters. This advice was both a source of comfort yet also of unease. On the one hand I felt the cases should have the freedom to tell 'their own story'. On the other hand I was filled with a great sense of ambiguity; I didn't really know how to make sense of and commit such complicated cases to paper with, at that point, rather rarefied insights and conclusions. The tension between two key commitments, firstly ensuring that the chapters were as robust and as coherent as possible, and secondly being 'true' to and considerate of the detailed cases and nuanced opinions of those I had engaged with, meant difficult judgements and trade-offs had to be contemplated, yet these were painful and a source of great unease.

I decided to initially write the case studies in as comprehensive a manner as possible. I started by reviewing the data and research material that had been generated in the field. I had somewhere in the region of 500,000 words, within personal note books and interview transcripts, and that excluded the countless e-mails, internal notes, memos, reports, applications for funding and business plans produced by the groups themselves, and policy documents issued by the myriad of statutory bodies that 
interacted with the cases. By the time I had compiled the first drafts of the cases they each amounted to around 60,000 words. They provided detailed descriptions of the many events that I deemed to be important in addressing my broad research questions, including lengthy quotes from interviews and documents. After the completion of my initial draft I was still unclear as to exactly which trajectory the research conclusions would take. I was, I admit, unsure about exactly what it was that my research said, an issue that would cause recurring problems. Here, Charmaz and Mitchell (2001:161) outline how ethnographic data may become unwieldy without critical engagement:

\begin{abstract}
A potential problem with ethnographic studies is seeing data everywhere and nowhere, gathering everything and nothing. The studied world seems so interesting (and probably is) that an ethnographer tries to master knowing it all. Mountains of unconnected data grow but they don't say much ... Ethnographers who leave data undigested seldom produce fresh insights and, sometimes, may not even complete their projects, despite years of toil.
\end{abstract}

It was difficult to deal with conflicting and subsidiary data as, whilst for the most part, my evidence base was unambiguous, there were occasions when interviewees and observations made slightly contradictory points or held opposing positions. Publications very often detail research that appears to be unequivocal and doubtless, yet I knew the shortcomings of my research all too well, and found it difficult to approach my own writing with such deep confidence. How can I, I constantly asked myself, report robust findings, but in a way that also is true to the intricacies of the research? As Yin (2003:164) notes:

The selectiveness is relevant in limiting the report to the most critical evidence and not cluttering the presentation with supportive but secondary information. Such selectiveness takes a lot of discipline among investigators, who usually want to display their entire evidentiary base, in the (false) hope that sheer volume or weight will sway the reader. (In fact, sheer volume or weight will bore the reader.)

I indeed felt this temptation to insert many similar quotes or 'data', precisely because it was self-affirming.

Due to their comprehensiveness, my two case study chapters had to be edited by around two thirds. Writing up suddenly was not as troublesome as 'deleting down'; I did not want to purge anything that could be useful later, and it was very difficult to delete sections where the composition had been so considered and upon which so much energy had been expended. At one point, and just for a moment, I gave serious consideration to throwing the chapters into the wind and keeping only those pages that I was able to retrieve before they were whipped away by the wind. But if only it were that easy! The torturous process of editing felt fraudulent - a betrayal of my time spent in the field, and the time expended by research participants for what to them undoubtedly seemed to be obtuse and esoteric academic interests. As I searched through and sorted sections of text, it all seemed important. There was always a nagging doubt as to whether the material I considered deleting really was surplus and I found it easier to leave sections in the text to deal with later on. It was all too easy to become stuck in the detail of the cases, to tweak at their edges without paying enough attention to the overarching themes through which the chapter narrative would be sustained. Ultimately, procrastination became my mechanism for avoiding decisionmaking and commitment. 
Data, we are reminded, is not collected but is generated (see May 2002), and as such it represents much more than just a story; it becomes 'our' story. I had, by now, worked with the material for a long time and developed a personal attachment to it. I wished to reflect both my efforts and the complicated nature of the groups and was therefore loathe to let any of it go. After the challenges of the fieldwork, I felt that the information I had obtained was 'hard won' and I even began to feel a little precious regarding my data. I found no easy way to approach the editing process. It was a long, hard and at times tedious slog. It involved taking a step back from my empirical work and trying to ensure that the chapters told a story that was both interesting and relevant to my key research themes. This allowed me to refocus the narrative, with priority and prominence being afforded to those points that were deemed to be most pertinent. As I redrafted, rewrote, gained feedback, and more importantly tightened and abridged the chapters, I gradually felt that the versions were becoming more coherent, not only helping build the chapters into more effective case studies, but also developing my own critiques and conclusions. In hindsight, I realise this editing and redrafting was itself an essential analytical tool and that writing my empirical work should therefore only have been completed in such an iterative fashion.

\section{Conclusion}

The move from the field to the desk to commence writing my thesis was not an easy one. Throughout my time in the field I had compiled notes and drafted broad narratives, yet when I began to think about writing chapters I found decisions concerning the inclusion or exclusion of material and the prospect of commitment to conclusions an immense challenge. As outlined, these difficulties were not only practical and intellectual but had also a personal and psychological dimension. I wanted to cling on to the familiar space of fieldwork, and found the prospect of making sense of my empirical work daunting. I had not, I felt at the time of leaving the field, had a chance to digest what I had witnessed and observed. The work felt incomplete and retaining links with my subjects was a source of comfort. Although it is useful to sustain links to the field, and indeed it may be unavoidable to do so, it is important to accept that other activities must be encountered. With time, and as I became more involved with the thesis, other issues regarding the case study chapters provided fresh challenges. I found it difficult to confine my research, and to recognise that boundaries must be drawn around the cases if I was to ever complete the thesis. As deadlines crept ever closer (and too frequently rushed by...), I recognised that my case study chapters, as with the thesis as a whole, would never be perfect. Compromises had to be made and I had to learn (indeed I continue to learn) how to tolerate the draft's inadequacies and the associated insecurities in my own ability that these created.

A thesis is, therefore, not only an academic enterprise, but also a personal voyage; the work often assumes an intimate quality. The cathexis created by 'our' research often means that it can be difficult to let go of material simply because we have become too close to our object of study and too attached to our findings. The concerns outlined here are not limited to writing and are indicative of many underlying demands that are inherent in doctoral research. They are also, I have learnt, the manifestation of the obligations and responsibilities we all face and must confront in the completion of the rite of passage that is a doctorate. 


\section{References}

Bacchiddu, G. 2004. Stepping between different worlds: reflections before, during and after fieldwork. Anthropology Matters Journal 6(2), www.anthropologymatters.com

Buchanan, D., D. Boddy and J. McCalman. 1998. Getting in, getting on, getting out and getting back. In Doing Research in Organizations (ed.) A. Bryman, 53-67. London: Routledge.

Charmaz, K. and R.G. Mitchell. 2001. Grounded theory in ethnography. In The Handbook of Ethnography (eds.) P. Atkinson, A. Coffey, S. Delamont, J. Lofland and L. Lofland, 160-174. London: Sage.

Hammersley, M. and P. Atkinson. 1983. Ethnography: Principles in Practice. London: Tavistock.

Hammersley, M. and P. Atkinson. 2006. Ethnography: Principles in Practice (2nd ed.). London: Routledge.

Josselson, R. 1996. On writing other people's lives: self analytic reflections of a narrative researcher. In Ethics and Process in the Narrative Study of Lives (ed.) R. Josselson, 60-71. Thousand Oaks, CA: Sage.

Lareau, A. 1996. Common problems in fieldwork: a personal essay. In Journeys Through Ethnography (eds.) A. Lareau and J. Shultz, 195-236. Boulder, CO: Westview.

May, T. 2002. Qualitative Research in Action. London: Routledge.

Murphy, E. and R. Dingwall. 2001. The ethics of ethnography. In The Handbook of Ethnography (eds.) P. Atkinson, A. Coffey, S. Delamont, J. Lofland and L. Lofland, 339-351. London: Sage.

Yin, R.K. 2003. Case Study Research: Design and Methods. Thousand Oaks, CA: Sage.

\section{Acknowledgements}

The author wishes to thank Sara Fuller and the reviewers for comments made on earlier drafts of this article. Thanks also to Ingie Hovland for facilitating and supporting the publishing process. The research was sponsored by the Economic and Social Research Council (ESRC), award number: PTA-030-2003-01134.

\section{About the author}

Paul O'Hare is currently finishing his $\mathrm{PhD}$ at the Department of Town \& Regional Planning at the University of Sheffield. He previously completed a BA in Geography and Politics at Queen's University, Belfast, before graduating from the University of Sheffield with an MA in Town Planning Research. His present research considers public participation in local decision making processes, particularly the role of collective action and the civic sector in community and neighbourhood governance. He can be contacted at either p.ohare@shef.ac.uk or paulohare@hotmail.com 